\title{
Association of Cigarette Smoking and Metabolic Syndrome in a Puerto Rican Adult Population
}

\author{
William A. Calo ${ }^{1}$, Ana P. Ortiz ${ }^{2,3}$, Erick Suárez ${ }^{3}$, Manuel Guzmán ${ }^{4}$, Carmen M. Pérez ${ }^{5}$, and \\ Cynthia M. Pérez ${ }^{3}$ \\ ${ }^{1}$ The University of Texas School of Public Health, Division of Management, Policy, and \\ Community Health, Houston, TX, USA \\ ${ }^{2}$ University of Puerto Rico Comprehensive Cancer Center, Division of Cancer Control and \\ Population Sciences, San Juan, PR, USA \\ ${ }^{3}$ University of Puerto Rico, Graduate School of Public Health, Department of Biostatistics and \\ Epidemiology, San Juan, PR, USA \\ ${ }^{4}$ University of Puerto Rico, School of Medicine, San Juan, PR, USA \\ ${ }^{5}$ Universidad del Turabo, School of Health Sciences, Gurabo, PR, USA
}

\begin{abstract}
Background-Metabolic syndrome (MetSyn) is related to an increased risk for type 2 diabetes and cardiovascular disease. Smokers are at greater risk than nonsmokers of becoming insulin resistant and to develop cardiovascular disease. This study aimed to explore the association between cigarette smoking, MetSyn and its components among Puerto Rican adults.
\end{abstract}

Methods-A representative sample of 856 persons aged 21-79 years from the San Juan Metropolitan area participated in this study. Demographic and lifestyle characteristics, including smoking habits, were gathered from a self-reported questionnaire. MetSyn was defined according to the revised NCEP-ATP III criteria and measured using biochemical measurements and anthropometric indices. Logistic regression models were used to estimate prevalence odds ratios (POR) and its 95\% confidence intervals (CI).

Results-MetSyn was significantly ( $\mathrm{p}<0.001)$ more prevalent in former smokers $(48.4 \%)$ as compared to current $(42.7 \%)$ and never smokers $(40.0 \%)$. However, after adjusting for possible confounders, current smokers who used more than 20 cigarettes per day were 2.24 (95\% CI= 1.00-4.99) times more likely to have MetSyn as compared to never smokers. Heavy smokers were also more likely to have high triglyceride levels (POR=2.22, 95\% CI=1.12-4.38) and low HDLcholesterol levels ( $\mathrm{POR}=2.49,95 \% \mathrm{CI}=1.28-4.86)$ as compared to never smokers.

Discussion-This study supports previous reports of an increased risk of MetSyn among current smokers, particularly those with a heavier consumption. Tobacco control strategies, such as preventing smoking initiation and disseminating evidence-based cessation programs, are necessary to reduce the burden of MetSyn in Puerto Rico.

\section{Keywords}

Metabolic syndrome; Smoking; Puerto Rico; Hispanics

Corresponding author: William A. Calo, Postdoctoral Fellow, University of Texas School of Public Health, 7000 Fannin, Room 2510G, Houston, Texas 77030, Phone: 713-500-9625 / Fax: 713-500-9750, william.a.calo@uth.tmc.edu. 


\section{INTRODUCTION}

Metabolic syndrome (MetSyn), a condition characterized by abdominal obesity, dyslipidemia, elevated blood pressure, and hyperglycemia, has become one of the major public health challenges worldwide [1]. This syndrome increases the risk of developing type 2 diabetes and cardiovascular disease and is correlated with all-cause mortality [2-3]. Also, accumulating evidence supports the notion that MetSyn is linked to various types of malignancies [4]. The pathogenesis of MetSyn is multifactorial, but the major underlying risk factors are obesity and insulin resistance [5]. Certain demographic characteristics and lifestyles, including smoking, have been identified as important modifiable risk factors for MetSyn and its individual components [6].

Cigarette smoking is a strong risk factor for atherosclerosis and cardiovascular disease in a dose-dependent relation [7]. Smoking has been reported to lower high-density lipoprotein cholesterol (HDL-C) and to increase low-density lipoprotein cholesterol (LDL-C) and triglycerides [6]. Also, smokers are at greater risk of developing insulin resistance [8-9] and subsequently diabetes than nonsmokers [10-12]. Therefore, smoking may also be considered as an important modifiable risk factor for MetSyn [13], supporting the need for intensified smoking cessation programs for patients with MetSynor its individual components [14].

In the United States (US), MetSyn is highly prevalent with an age-standardized prevalence of $34.0 \%$ among adults aged 20 years and older [15]. Nevertheless, the prevalence varies by racial/ethnic groups and gender, being more prevalent among Mexican Americans. Forty percent of Mexican American women have MetSyn, a higher prevalence than the reported fornon-Hispanic White (31.5\%) and non-Hispanic Black (38.8\%) women. MetSynis also more prevalent among Mexican American men (33.2\%) than in their non-Hispanic Black counterparts (25.3\%). Interestingly, MetSyn prevalence estimates are as high as 50\% for Puerto Ricans elders living in Massachusetts [16]. It is also well known that for certain health conditions associated with MetSyn, such as overweight and obesity, Hispanics bear a disproportionate burden, and they experience more age-adjusted years of potential life lost before the age of 75 years (per 100,000 people) for stroke and diabetes when compared to non-Hispanic Whites [17]. Despite the existence of multiple Hispanic subgroups in the US, the age-adjusted prevalence of MetSyn has been estimated only for Mexican Americans [15] and the majority of epidemiologic research among Hispanics has focused primarily on the same group [18]. Thus, examining the burden of a disease by aggregating data of different Hispanic groups or not taking into account one of them may obscure variations in health outcomes due to differences in demographics, lifestyles, and cultural factors [19].

A recent population-based study conducted in the San Juan Metropolitan Area, Puerto Rico showed that $42.1 \%$ of adult men and $36.4 \%$ of women have MetSyn [20]. These ageadjusted prevalence' sare higher than the reported for other racial/ethnic groups in the US [15]. These findings are consistent with previous observations that Puerto Ricans are more affected by diabetes than are other racial/ethnic groups [17, 21-22]. Health behaviors, such as smoking, and health outcomes, such as MetSyn, vary considerably among Hispanic groups $[15,17,20]$. To date, the relationship between cigarette smoking and MetSyn has not been studied in depth for Puerto Rican islanders. Given the high burden of diabetes and MetSynin Puerto Rico, we aimed to study the association of cigarette smoking with MetSyn and its individual components in a sample of Puerto Rican adults. 


\section{METHODS}

\section{Participants}

The study population consisted of 856 adults aged 21-79 years, who participated in a population-based cross-sectional study conducted from 2005 to 2007 in the San Juan Metropolitan Area of Puerto Rico [20]. The sampling frame was based on Census tracks maps, and the sampling procedure was a cluster design for household surveys [23]. A threestage sampling design was used as described elsewhere [20]. All individuals aged 21-79 years from each selected household were eligible to participate in the study and asked to undergo a personal interview, physical exam, and biochemical measurements.

\section{Data collection and measures}

Adults who consented to participate in the study were instructed to fast for at least 8-12 hours before their morning appointment in a mobile examination center located near their homes. A questionnaire that collected demographic and lifestyle characteristics was administered. Information on age, sex, education level, annual family income, and health insurance coverage was collected. Information on participants' smoking habits was also obtained. Participants were considered current smokers if they reported having smoked at least 100 cigarettes during their lifetime and were still smoking [24]. Information on daily cigarette consumption was used to define the amount of cigarettes smoked per day $(1-9,10-$ $19,220)$ among current smokers. Former smokers were defined as those who had previously smoked 100 or more cigarettes and have stopped smoking. Participants who reported having at least one drink of any type of alcohol during the past 30 days were considered current drinkers. Respondents were classified as meeting national guidelines on physical activity if they reported participation in moderate-intensity activities for 30 minutes on five days per week or vigorous-intensity for at least 20 minutes on three days per week [25].

MetSyn was defined based on the American Heart Association/National Heart, Lung, and Blood Institute revised definition of the NCEP-ATP III report [5]. According to this definition, participants with three or more of the following five criteria have MetSyn: (1) abdominal obesity determined by elevated waist circumference ( $\geq 40$ inches in men and $\geq 35$ inches in women); (2) elevated triglycerides ( $>150 \mathrm{mg} / \mathrm{dL}$ ) or on drug treatment for hypertriglyceridemia; (3) reduced HDL-C ( $<40 \mathrm{mg} / \mathrm{dL}$ in men and $<50 \mathrm{mg} / \mathrm{dL}$ in women) or on drug treatment for reduced HDL-C; (4) elevated blood pressure (systolic blood pressure $\geq 130 \mathrm{~mm} \mathrm{Hg}$ or diastolic blood pressure $\geq 85 \mathrm{~mm} \mathrm{Hg}$ ) or on antihypertensive drug treatment; and (5) elevated fasting glucose ( $\geq 100 \mathrm{mg} / \mathrm{dL}$ ) or on drug treatment for elevated glucose.

Anthropometric measurements were evaluated for height, body weight, and waist and hip circumferences. Waist circumference was determined with a measuring tape at the high point of the iliac crest at minimal respiration. A Cardinal Detecto digital scale (Cardinal/ Detecto, Webb City, MO) was used to measure current body weight in kilograms, and a portable Seca stadiometer (Seca Corporation, Hanover, MD) was used to determine height in meters. Body mass index (BMI) categories were defined as underweight $\left(<18.5 \mathrm{~kg} / \mathrm{m}^{2}\right)$, normal $\left(18.5-24.9 \mathrm{~kg} / \mathrm{m}^{2}\right)$, overweight $\left(25.0-29.9 \mathrm{~kg} / \mathrm{m}^{2}\right)$, and obese $\left(\geq 30.0 \mathrm{~kg} / \mathrm{m}^{2}\right)$.

Three blood pressure measurements were taken 10 minutes apart using an appropriate cuff size and a standard aneroid sphygmomanometer. Blood pressure status was based on the average of the three measurements. Fasting blood samples were collected, centrifuged, refrigerated at the mobile examination center, and transferred in iceboxes to a local reference laboratory on the day taken for analyses. Concentrations of total cholesterol, triglycerides, HDL-C, and fasting plasma glucose were determined using commercial enzymatic colorimetric kits (Bayer Diagnostics, Tarrytown, NY). The study was approved 
by the Institutional Review Board of the University of Puerto Rico Medical Sciences Campus.

\section{Statistical analysis}

Age-adjusted means and percentages were used to characterize the study population. Chisquare statistics were generated to compare the distribution of MetSyn and its individual components across smoking status. Analysis of variance was used to compare continuous variables according to smoking categories. Multiple-comparison procedures for linear contrasts were used to assess differences between age-adjusted means. Logistic regression models, with the use of the generalized estimating equations, were constructed to estimate the prevalence odds ratios (POR) with $95 \%$ confidence. The parameters estimation of this model was done using the generalized estimating equations in order to control for the intraclass correlation among subjects of the same block. A sandwich estimate of variance was used to determine the standard errors of the logistic regression parameters [26]. All possible first-order interactions in the logistic model were assessed with the use of the likelihood ratio test. Separate multiple logistic regression models were run to evaluate the association of cigarette smoking status with MetSyn and its individual components after adjusting for covariates. All analyses were performed incorporating the sampling weights to obtain unbiased estimates from the complex sampling design using Stata 10.0 (StataCorp, College Station, Texas).

\section{RESULTS}

Sixty-one percent of the participants had never smoked, $18.8 \%$ were former smokers, and $20.0 \%$ currently smoke (Table 1$)$. The majority of current smokers were women $(\mathrm{P}<0.001)$, younger than never and former smokers $(\mathrm{P}<0.001)$, and they had the lowest annual family income $(\mathrm{P}=0.008)$ and health insurance coverage $(\mathrm{P}<0.001)$. This group also had the highest percentage of current drinking $(\mathrm{P}<0.001)$ but they were the most physically active group $(\mathrm{P}=0.002)$ and they also had the lowest mean BMI $(\mathrm{P}=0.047)$. Former smokers had the highest prevalence of abdominal obesity, elevated triglycerides higher blood pressure, and increased fasting glucose $(\mathrm{P}<0.001)$. Low HDL-C was more prevalent in current smokers $(\mathrm{P}<0.001)$. MetSyn was more prevalent in former smokers $(\mathrm{P}<0.001)$. MetSyn was more prevalent in men who were former smokers $(56.7 \%, \mathrm{P}=0.03)$ than current $(43.7 \%)$ and never smokers (39.1\%); and more prevalent among women who were former smokers $(53.5 \%, \mathrm{P}=0.01)$ as compared to current (31.0\%) and never smokers (42.2\%) (data not shown).

Mean concentrations for triglycerides, glucose, systolic and diastolic blood pressures, and waist circumference were significantly higher $(\mathrm{P}<0.05)$ in former smokers when compared to never smokers (Table 2). Compared to current smokers that smoked 1-9 cigarettes daily, former smokers had higher mean concentrations of triglycerides, glucose, and systolic blood pressure $(\mathrm{P}<0.05)$. Waist circumference was significantly higher $(\mathrm{P}<0.05)$ in former smokers when compared to current smokers that smoked 1-9,10-19, and $\geq 20$ cigarettes daily.

In logistic regression models, simultaneously adjusting for sex, age, education, health insurance coverage, current alcohol consumption, physical activity and BMI, no significant differences were observed in the occurrence of MetSyn between former and never smokers (Table 3). Although the odds ratio of MetSyn increased with the number of cigarettes smoked per day, the difference with never smokers was significant only among those who smoked $\geq 20$ cigarettes per day ( $\mathrm{POR}=2.24,95 \% \mathrm{CI}=1.00-4.99$ ). This group of heavy smokers were also more likely to have high triglyceride levels ( $\mathrm{POR}=2.22 ; 95 \% \mathrm{CI}=1.12$ 4.38) and low HDL-C levels ( $\mathrm{POR}=2.49 ; 95 \% \mathrm{CI}=1.28-4.86)$ as compared to never 
smokers. Former smokers who quit between 11-20 years ago were 2.42 more likely ( $95 \%$ $\mathrm{CI}=1.07-5.49)$ to have MetSyn as compared to never smokers but no association was found for those who had stopped smoking $\leq 10$ years ago and $\geq 20$ years ago (data not shown). There was a significant dose-dependent association between the amount of cigarettes smoked and high triglyceride levels $(\mathrm{P}$ for trend $=0.03$ ) and a marginally significant dosedependent association for low HDL-C levels ( $\mathrm{P}$ for trend=0.07).

\section{DISCUSSION}

In this cross-sectional study, we observed that the prevalence of MetSyn was highest in former smokers than in current smokers. This finding is consistent with previous longitudinal studies [27-29]. It has been found that MetSyn remains for at least 10 years and over in people who smoked 20 or more cigarettes per day before quitting, and for over 20 years in those who smoked 40 cigarettes or more daily [29]. Research also has shown that people who quit smoking are likely to gain weight [30]. Indeed, the increase in the prevalence of overweight and obesity in the US has been attributed in part to smoking cessation [31]. The mechanism of weight gain after quitting smoking includes increased energy intake, decreased resting metabolic rate, decreased physical activity, and increased lipoprotein lipase activity [32]. Thus, the high prevalence of MetSyn in former smokers could be explained by the subsequent body weight gain after quitting [29]. An alternative explanation is that our findings are subject to reverse causation due to the cross-sectional design used. MetSyn was also more prevalent in men who were former smokers when compared to current smokers. This finding is in disagreement with previous research [3335] buta recent study conducted among Japanese men found no difference in the prevalence of MetSyn among current and former smokers [36].

Nonetheless, in covariate-adjusted analysis, current smokers consuming at least 20 cigarettes per day were 2.24 times more likely to have MetSyn as compared to never smokers. This association could be explained by the strong observed associations between heavy smoking status ( $\geq 20$ cigarettes per day) and abnormalities in triglyceride and HDL-C levels. Our results showed a positive dose-dependent association between smoking and high triglyceride levels and a marginally significant dose-dependent association with low HDL-C levels, a finding that is also consistent with previous studies [8, 33-34, 36-37]. Heavy smokers use more lipids to sustain fasting resting energy expenditure than nonsmokers [30]. Then, if people quit smoking but do not decrease their lipid consumption, over time, the imbalance lipid intake and fat oxidation may cause an increase in body weight. Research has found that triglycerides are a risk factor for cardiovascular disease independent of HDL-C [38]. Also, an independent inverse association of HDL-C levels and ischemic coronary heart disease event rates has been documented [39].

In our study, the overall prevalence of elevated fasting glucose was higher among former smokers than among current smokers, although we did not find an association between smoking and high fasting plasma glucose in the covariate-adjusted analysis. Our study also showed that smoking was not associated with abdominal obesity. This finding is consistent with previous studies [33-34] but inconsistent with several others [10, 40-41]. Crosssectional studies have demonstrated that abdominal obesity is higher in smokers than in nonsmokers [41-42]. Abdominal obesity is positively associated with the number of cigarettes smoked and pack-years of smoking [41]. In former smokers, abdominal obesity is negatively associated with the time since quitting [41]. The combination of a high waist to hip ratio with a low BMI, which some authors consider a "paradox", is also more frequent in smokers than in nonsmokers [42]. 
In the covariate-adjusted analysis, no association between smoking and high blood pressure was found. Although it has been widely reported that smoking acutely increases blood pressure and may lead to hypertension [43-44], other studies have reported that blood pressure is lower in smokers than in nonsmokers [45]. Moreover, other studies have speculated about the effects of smoking on blood pressure on the basis of changes in blood pressure that were observed after smoking cessation. One of these studies reported that blood pressure rose after smoking cessation [46], while others reported that smoking cessation had no clear-cut effect on blood pressure level [47-48].

The strengths of this study include that the study population was a representative sample of Puerto Ricans adults living in the San Juan Metropolitan Area, and that the associations of interest were adjusted for relevant covariates. Also, other strength of this study is that the criteria used to define metabolic syndrome, based on the NCEP-ATP III, have shown a good concordance with other instruments, such as the International Diabetes Federation criteria [49]. However, potential limitations still remain in our study. First, the smoking status was based on self-reported information; thus, results are subject to misclassification bias. Second, an inherent limitation of a cross-sectional design is the inability to establish a temporal relation between smoking and MetSyn and its components. Nonetheless, our results are consistent with previous studies performed in other populations. Finally, the study did not measure the risk of developing MetSyn after smoking cessation because data on the number of cigarettes smoked before quitting was not collected. Nonetheless, this study adds valuable evidence to the literature on the association of cigarette smoking and MetSyn for a Hispanic group of homogenous origin like Puerto Rican islanders.

In conclusion, this study supports the view that the odds of MetSynare greater in heavy smokers than in never smokers, and that this increased risk appears to be driven by abnormalities in triglycerides and HDL-C rather than the presence of high blood pressure, abnormal fasting glucose, or abdominal obesity. Further longitudinal studies are needed to elucidate the underlying mechanisms and the effect of smoking on MetSyn among Puerto Ricans. Tobacco control strategies in Puerto Rico must focus on the prevention of smoking initiation among young adults, as well as smoking cessation programs among smokers, in order to reduce the burden of MetSyn, its individual components and of their related comorbidities. System-level changes must take place to integrate the identification of smokers and the dissemination of evidence-based cessation treatments into the routine delivery of health care with a more proactive approach with those at risk of developing MetSyn.

\section{Acknowledgments}

This project was funded by an unrestricted grant from Merck Sharp \& Dohme Corporation with additional support from the National Center for Research Resources (U54 RR 026139-01A1) and the National Institute on Minority Health and Health Disparities (8U54 MD 007587-03) from the National Institutes of Health, the Case Comprehensive Cancer Center Training in Computational Genomic Epidemiology of Cancer (5R25CA094186-08), and the Puerto Rico Cancer Center / MD Anderson Cancer Center, Partners for Excellence in Cancer Research (U54CA96297). WAC was supported by a Post-doctoral Fellowship from The University of Texas School of Public Health, Cancer Education and Career Development Program (2R25-CA057712). We would like to acknowledge Dr. Li Li from Case Comprehensive Cancer Center at Case Western University, and the faculty and students from The University of Texas School of Public Health, Behavioral Sciences Doctoral Seminar for their contribution reviewing this manuscript.

\section{REFERENCES}

1. Alberti KG, Eckel RH, Grundy SM, Zimmet PZ, Cleeman JI, Donato KA, et al. Harmonizing the metabolic syndrome: a joint interim statement of the International Diabetes Federation Task Force on Epidemiology and Prevention; National Heart, Lung, and Blood Institute; American Heart 
Association; World Heart Federation; International Atherosclerosis Society; international association for the Study of Obesity. Circulation. 2009; 120(16):1640-1645. [PubMed: 19805654]

2. Wilson PW, D'Agostino RB, Parise H, Sullivan L, Meigs JB. Metabolic syndrome as a precursor of cardiovascular disease and type 2 diabetes mellitus. Circulation. 2005; 112(20):3066-3072. [PubMed: 16275870]

3. Lakka HM, Laaksonen DE, Lakka TA, Niskanen LK, Kumpusalo E, Tuomilehto J, et al. The metabolic syndrome and total and cardiovascular disease mortality in middle-aged men. JAMA. 2002; 288(21):2709-2716. [PubMed: 12460094]

4. Pothiwala P, Jain SK, Yaturu S. Metabolic Syndrome and Cancer. Metab Syndr Relat Disord. 2009; 7(4):279-288. [PubMed: 19284314]

5. Grundy SM, Cleeman JI, Daniels SR, Donato KA, Eckel RH, Franklin BA, et al. Diagnosis and management of the metabolic syndrome: an American Heart Association/National Heart, Lung, and Blood Institute Scientific Statement. Circulation. 2005; 112(17):2735-2752. [PubMed: 16157765]

6. Lee WY, Jung CH, Park JS, Rhee EJ, Kim SW. Effects of smoking, alcohol, exercise, education, and family history on the metabolic syndrome as defined by the ATP III. Diabetes Res Clin Pract. 2005; 67(1):70-77. [PubMed: 15620436]

7. Kannel WB. Update on the role of cigarette smoking in coronary artery disease. Am Heart J. 1981; 101(3):319-328. [PubMed: 7008566]

8. Facchini FS, Hollenbeck CB, Jeppesen J, Chen YD, Reaven GM. Insulin resistance and cigarette smoking. Lancet. 1992; 339(8807):1128-1130. [PubMed: 1349365]

9. Ronnemaa T, Ronnemaa EM, Puukka P, Pyorala K, Laakso M. Smoking is independently associated with high plasma insulin levels in nondiabetic men. Diabetes Care. 1996; 19(11):1229-1232. [PubMed: 8908385]

10. Foy CG, Bell RA, Farmer DF, Goff DC Jr, Wagenknecht LE. Smoking and incidence of diabetes among U.S. adults: findings from the Insulin Resistance Atherosclerosis Study. Diabetes Care. 2005; 28(10):2501-2507. [PubMed: 16186287]

11. Rimm EB, Chan J, Stampfer MJ, Colditz GA, Willett WC. Prospective study of cigarette smoking, alcohol use, and the risk of diabetes in men. BMJ. 1995; 310(6979):555-559. [PubMed: 7888928]

12. Hu FB, Manson JE, Stampfer MJ, Colditz G, Liu S, Solomon CG, et al. Diet, lifestyle, and the risk of type 2 diabetes mellitus in women. N Engl J Med. 2001; 345(11):790-797. [PubMed: 11556298]

13. Miyatake N, Wada J, Kawasaki Y, Nishii K, Makino H, Numata T. Relationship between metabolic syndrome and cigarette smoking in the Japanese population. Intern Med. 2006; 45(18): 1039-1043. [PubMed: 17043374]

14. Dzien A, Dzien-Bischinger C, Hoppichler F, Lechleitner M. The metabolic syndrome as a link between smoking and cardiovascular disease. Diabetes Obes. Metab. 2004; 6(2):127-132. [PubMed: 14746578]

15. Ervin, RB. National Health Statistics Reports; no 13. Hyattsville, MD: National Center for Health Statistics; 2009. Prevalence of metabolic syndrome among adults 20 years of age and over, by sex, age, race and ethnicity, and body mass index: United States 2003-2006.

16. Gao X, Nelson ME, Tucker KL. Television viewing is associated with prevalence of metabolic syndrome in Hispanic elders. Diabetes Care. 2007; 30(3):694-700. [PubMed: 17327343]

17. Centers for Disease Control and Prevention (CDC). Health disparities experienced by Hispanics-United States. MMWR Morb Mortal Wkly Rep. 2004; 53(40):935-937. [PubMed: 15483525]

18. Noel SE, Newby PK, Ordovas JM, Tucker KL. A traditional rice and beans pattern is associated with metabolic syndrome in Puerto Rican older adults. J Nutr. 2009; 139(7):1360-1367. [PubMed: 19458029]

19. Pérez-Escamilla R, Putnik P. The role of acculturation in nutrition, lifestyle, and incidence of type 2 diabetes among Latinos. J Nutr. 2007; 137(4):860-870. [PubMed: 17374645]

20. Pérez CM, Guzmán M, Ortiz AP, Estrella M, Valle Y, Pérez N, et al. Prevalence of the metabolic syndrome in San Juan, Puerto Rico. Ethn Dis. 2008; 18(4):434-441. [PubMed: 19157247]

21. Centers for Disease Control and Prevention (CDC). State-specific incidence of diabetes among adults-participating states: 1995-1997 and 2005-2007. MMWR Morb Mortal Wkly Rep. 2008; 57(43):1169-1173. [PubMed: 18971918] 
22. Caballero AE. Diabetes in the Hispanic or Latino population: genes, environment, culture, and more. Curr Diab Rep. 2005; 5(3):217-225. [PubMed: 15929869]

23. Kish, L. Survey Sampling. New York: John Wiley \& Sons, Inc; 1967.

24. Garrett BE, Dube SR, Trosclair A, Caraballo RS, Pechacek TF. Centers for Disease Control and Prevention. Cigarette smoking - United States, 1965-2008. MMWR Surveill Summ. 2011; 60(Suppl):109-113. [PubMed: 21430635]

25. Haskell WL, Lee IM, Pate RR, Powell KE, Blair SN, Franklin BA, et al. Physical activity and public health: updated recommendation for adults from the American College of Sports Medicine and the American Heart Association. Circulation. 2007; 116(9):1081-1093. [PubMed: 17671237]

26. Hardin, JW.; Hilbe, JM. Generalized Estimating Equations. Boca Raton, Fla: Chapman \& Hall/ CRC; 2003.

27. Onat A, Uğur M, Hergenç G, Can G, Ordu S, Dursunoğlu D. Lifestyle and metabolic determinants of incident hypertension, with special reference to cigarette smoking: a longitudinal populationbased study. Am J Hypertens. 2009; 22(2):156-162. [PubMed: 19039311]

28. Al-Daghri NM. Acute post cessation smoking: A strong predictive factor for metabolic syndrome among adult Saudis. Saudi Med J. 2009; 30(2):267-271. [PubMed: 19198718]

29. Wada T, Urashima M, Fukumoto T. Risk of metabolic syndrome persists twenty years after the cessation of smoking. Intern Med. 2007; 46(14):1079-1082. [PubMed: 17634703]

30. Filozof C, FernándezPinilla MC, Fernández-Cruz A. Smoking cessation and weight gain. Obes Rev. 2004; 5(2):95-103. [PubMed: 15086863]

31. Flegal KM, Troiano RP, Pamuk ER, Kuczmarski RJ, Campbell SM. The influence of smoking cessation on the prevalence of overweight in the United States. N Engl J Med. 1995; 333(18): 1165-1170. [PubMed: 7565970]

32. Chiolero A, Faeh D, Paccaud F, Cornuz J. Consequences of smoking for body weight, body fat distribution, and insulin resistance. Am J Clin Nutr. 2008; 87(4):801-809. [PubMed: 18400700]

33. Oh SW, Yoon YS, Lee ES, Kim WK, Park C, Lee S, et al. Association between cigarette smoking and metabolic syndrome: the Korea National Health and Nutrition Examination Survey. Diabetes Care. 2005; 28(8):2064-206. [PubMed: 16043763]

34. Chen CC, Li TC, Chang PC, Liu CS, Lin WY, Wu MT, et al. Association among cigarette smoking, metabolic syndrome, and its individual components: the metabolic syndrome study in Taiwan. Metabolism. 2008; 57(4):544-548. [PubMed: 18328358]

35. Tonstad S, Svendsen M. Premature coronary heart disease, cigarette smoking, and the metabolic syndrome. Am J Cardiol. 2005; 96(12):1681-1685. [PubMed: 16360357]

36. Nakashita Y, Nakamura M, Kitamura A, Kiyama M, Ishikawa Y, Mikami H. Relationships of cigarette smoking and alcohol consumption to metabolic syndrome in Japanese men. J Epidemiol. 2010; 20(5):391-397. [PubMed: 20699598]

37. Ishizaka N, Ishizaka Y, Toda E, Hashimoto H, Nagai R, Yamakado M. Association between cigarette smoking, metabolic syndrome, and carotid arteriosclerosis in Japanese individuals. Atherosclerosis. 2005; 181(2):381-388. [PubMed: 16039294]

38. Hokanson JE, Austin MA. Plasma triglyceride level is a risk factor for cardiovascular disease independent of high-density lipoprotein cholesterol level: a meta-analysis of population-based prospective studies. J Cardiovasc Risk. 1996; 3(2):213-219. [PubMed: 8836866]

39. Gordon DJ, Probstfield JL, Garrison RJ, Neaton JD, Castelli WP, Knoke JD, et al. High-density lipoprotein cholesterol and cardiovascular disease: Four prospective American studies. Circulation. 1989; 79(1):8-15. [PubMed: 2642759]

40. Bamia C, Trichopoulou A, Lenas D, Trichopoulos D. Tobacco smoking in relation to body fat mass and distribution in a general population sample. Int J Obes Relat Metab Disord. 2004; 28(8): 1091-1096. [PubMed: 15197410]

41. Canoy D, Wareham N, Luben R, Welch A, Bingham S, Day N, et al. Cigarette smoking and fat distribution in 21,828 British men and women: a population-based study. Obes Res. 2005; 13(8): 1466-1475. [PubMed: 16129730]

42. Jee SH, Lee SY, Nam CM, Kim SY, Kim MT. Effect of smoking on the paradox of high waist-tohip ratio and low body mass index. Obes Res. 2002; 10(9):891-895. [PubMed: 12226137] 
43. Mundal R, Kjeldsen SE, Sandvik L, Erikssen G, Thaulow E, Erikssen J. Predictors of 7-year changes in exercise blood pressure: effects of smoking, physical fitness and pulmonary function. $\mathrm{J}$ Hypertens. 1997; 15(3):245-249. [PubMed: 9468451]

44. Niskanen L, Laaksonen DE, Nyyssönen K, Punnonen K, Valkonen VP, Fuentes R, et al. Inflammation, abdominal obesity, and smoking as predictors of hypertension. Hypertension. 2004; 44(6):859-865. [PubMed: 15492131]

45. Green MS, Harari G. A prospective study of the effects of changes in smoking habits on blood count, serum lipids and lipoproteins, body weight and blood pressure in occupationally active men. The Israeli CORDIS Study. J Clin Epidemiol. 1995; 48(9):1159-1166. [PubMed: 7636518]

46. Wilhelmsen L, Berglund G, Elmfeldt D, Tibblin G, Wedel H, Pennert K, et al. The multifactor primary prevention trial in Göteborg, Sweden. Eur Heart J. 1986; 7(4):279-288. [PubMed: 3720755]

47. Tuomilehto J, Nissinen A, Puska P, Salonen JT, Jalkanen L. Long-term effects of cessation of smoking on body weight, blood pressure and serum cholesterol in the middle-aged population with high blood pressure. Addict Behav. 1986; 11(1):1-9. [PubMed: 3716910]

48. Green MS, Harari G, Schwartz K. Cigarette smoking related to ambulatory blood pressure and heart rate. Am Heart J. 1991; 121(5):1569-1570. [PubMed: 2017998]

49. Zainuddin LR, Isa N, Muda WM, Mohamed HJ. The prevalence of metabolic syndrome according to various definitions and hypertriglyceridemic-waist in Malaysian adults. Int J Prev Med. 2011; 2(4):229-237. [PubMed: 22174962] 
Table 1

Characteristics of the study participants according tosmoking status*

\begin{tabular}{|c|c|c|c|c|}
\hline Characteristics & Never $(n=524)$ & Former $(n=161)$ & Current (n=171) & P value \\
\hline Women & $391(74.6)$ & $71(44.4)$ & $100(58.2)$ & $<0.001$ \\
\hline Age, years & $49.7 \pm 16.3$ & $56.1 \pm 15.0$ & $42.2 \pm 13.6$ & $<0.001$ \\
\hline Educational level, years & & & & $<0.001$ \\
\hline$<12$ & $129(24.7)$ & $55(32.4)$ & $59(34.2)$ & \\
\hline $12-15$ & $282(54.0)$ & $77(52.0)$ & $86(51.2)$ & \\
\hline $16+$ & $113(21.3)$ & $29(15.6)$ & $26(14.6)$ & \\
\hline Annual family income & & & & 0.008 \\
\hline$<\$ 20,000$ & $310(66.8)$ & $90(60.4)$ & $103(74.2)$ & \\
\hline $2 \$ 20,000$ & $154(33.2)$ & $53(39.6)$ & $40(25.8)$ & \\
\hline Health insurance coverage & & & & $<0.001$ \\
\hline Private & $308(60.0)$ & $107(65.6)$ & $52(30.4)$ & \\
\hline Government & $176(32.5)$ & $38(28.4)$ & $80(48.0)$ & \\
\hline No insurance & $40(7.5)$ & $161(6.0)$ & 39 (21.6) & \\
\hline Current drinker & $187(35.7)$ & $79(52.7)$ & $123(69.1)$ & $<0.001$ \\
\hline Physically active & $198(37.8)$ & $52(33.9)$ & $81(45.2)$ & 0.002 \\
\hline Body mass index, $\mathrm{kg} / \mathrm{m}^{2}$ & $29.8 \pm 0.3$ & $30.3 \pm 0.5$ & $28.6 \pm 0.4$ & 0.047 \\
\hline C-reactive protein, $\mathrm{mg} / \mathrm{L}$ & & & & 0.07 \\
\hline$\unlhd) .16$ & $178(34.7)$ & $56(33.7)$ & $53(30.8)$ & \\
\hline $0.17-0.48$ & $177(33.1)$ & $50(33.2)$ & $50(33.0)$ & \\
\hline \). 49 & $166(32.2)$ & $55(33.1)$ & $63(36.2)$ & \\
\hline \multicolumn{5}{|c|}{ Metabolic syndrome components } \\
\hline Abdominal obesity & $267(50.8)$ & $85(49.7)$ & $65(41.1)$ & $<0.001$ \\
\hline Elevated triglycerides & $153(28.3)$ & $67(37.3)$ & $48(31.3)$ & $<0.001$ \\
\hline Low HDL-C & $241(46.0)$ & $64(42.4)$ & $88(48.3)$ & $<0.001$ \\
\hline Elevated blood pressure & $241(43.5)$ & $102(53.4)$ & $47(35.0)$ & $<0.001$ \\
\hline Elevated fasting glucose & $251(47.1)$ & $104(58.2)$ & $71(49.8)$ & $<0.001$ \\
\hline Metabolic syndrome & $217(40.0)$ & $89(48.4)$ & $62(42.7)$ & $<0.001$ \\
\hline
\end{tabular}


